
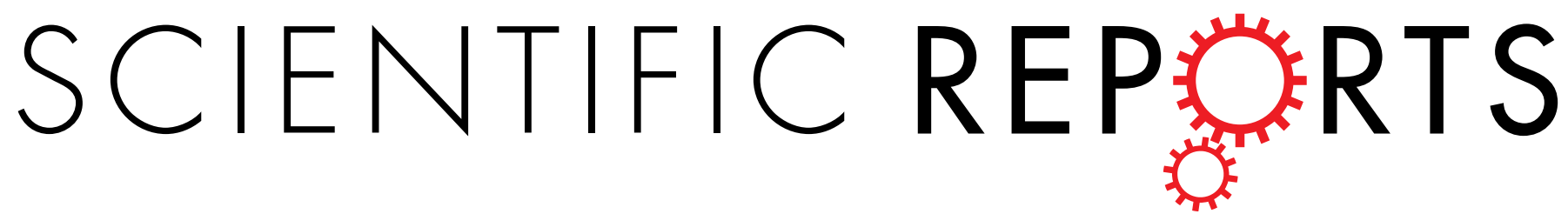

\title{
OPEN ADHD-associated risk taking is linked to exaggerated views of the benefits of positive outcomes
}

Received: 03 June 2016

Accepted: 15 September 2016

Published: 11 October 2016

\author{
Rachel Shoham ${ }^{1,2}$, Edmund J. S. Sonuga-Barke ${ }^{3,4}$, Hamutal Aloni ${ }^{1}$, Ilan Yaniv ${ }^{1,5}$ \& \\ Yehuda Pollak 6
}

Attention deficit and hyperactivity disorder (ADHD) is often assumed to be associated with increased engagement in risk-taking behaviors. The current study sought to understand the mental processes underlying this association using a theory-driven behavioral economics perspective. Psychological riskreturn models suggest that risk and benefit are inherently subjective, and risk taking is best understood as the interplay between cognitions and motivations regarding the benefits and risks of alternatives. A sample of 244 adults was assessed for ADHD symptoms. The likelihood of engagement in a range of risky behaviors (e.g., driving without wearing a seat belt), the magnitude of perceived benefit and risk ascribed to these behaviors, and benefit and risk attitudes of each participant were extracted from the Domain Specific Risk Taking (DOSPERT) scales. ADHD symptoms were correlated with more risky behaviors and perception of greater benefits from engaging in these behaviors, but were not correlated with risk perception. Mediation analysis revealed that the association between ADHD symptoms and engagement in risk taking was mediated by perceived benefits. These findings highlight the idea that people with high level ADHD symptoms tend to engage in risky behaviors because they find such behavior particularly appealing, rather than because they seek risk per se.

Attention deficit and hyperactivity disorder (ADHD) is a neurodevelopmental disorder, characterized by a persistent pattern of inattentive, hyperactive and impulsive behavior, interfering with educational, social and occupational functioning ${ }^{1,2}$. Individuals diagnosed with ADHD tend to engage deliberately in behaviors that place them at risk for negative outcomes ${ }^{3}$ including smoking ${ }^{4}$, substance abuse $e^{5-7}$, dangerous driving ${ }^{8}$, gambling ${ }^{9}$ and unprotected $\operatorname{sex}^{10}$.

The present study takes the perspective of a behavioral economics ${ }^{11,12}$ in an attempt to understand the mental processes that might account for risk taking in ADHD. Behavioral economic approaches see the individual as an active agent who makes preferences based on calculation of the expected utility of the available alternatives. According to the normative expected utility framework, the expected value of a risky alternative comprises its subjective potential payoff weighted by its probability. A rational decision maker should calculate the expected value of each available alternative and consistently choose the one with the highest expected value. An important construct of this theory is Risk attitude, namely, a person's position on the continuum from risk aversion to risk seeking; risk attitude is reflected in the shape of the person's utility function, which is commonly considered a personality trait ${ }^{13}$.

In proposing their version of behavioral decision theory (BDT), Weber, Blais, and Betz's ${ }^{11}$ maintained that risk and benefit are inherently subjective, and that individuals make decisions based on their perceptions of the costs and benefits of the alternatives as well as their attitudes toward these perceived cost and benefit ${ }^{11}$. Risk/ benefit perception is defined as the magnitude of riskiness/benefit a person ascribes to an alternative, whereas perceived risk/benefit attitude refers to how much the person is attracted or repelled by her perceived risk/benefit, or how much her risk taking is affected by her risk and benefit perceptions ${ }^{11}$. People may take risks because they perceive the risk to be low and/or the benefits to be high, or alternatively, because their risk aversion is low and/or

${ }^{1}$ Department of Psychology, The Hebrew University of Jerusalem, Jerusalem, Israel. ${ }^{2}$ Special Education department, Talpiot College, Holon, Israel. ${ }^{3}$ Developmental Brain-Behaviour Laboratory, University of Southampton, UK. ${ }^{4}$ Department of Experimental, Clinical and Health Psychology, Ghent University, Belgium. ${ }^{5}$ Federmann Center for Study of Rationality, The Hebrew University of Jerusalem, Jerusalem, Israel. ${ }^{6}$ The Seymour Fox School of Education, The Hebrew University of Jerusalem, Jerusalem, Israel. Correspondence and requests for materials should be addressed to Y.P. (email: yehuda.pollak@mail.huji.ac.il) 


\begin{tabular}{|c|c|c|}
\hline & Median & $25-75 \%$ \\
\hline ASRS & 43 & $37-50$ \\
\hline inattention & 22 & $18-27$ \\
\hline hyperactivity & 21 & $17-25$ \\
\hline \multicolumn{3}{|l|}{ DOSPERT scales } \\
\hline Risk-Taking & 2.83 & $2.33-3.27$ \\
\hline Benefit-Perception & 2.67 & $2.20-3.16$ \\
\hline Risk-Perception & 4.33 & $3.87-4.80$ \\
\hline Perceived-benefit Attitude & 0.39 & $0.21-0.61$ \\
\hline Perceived-risk Attitude & -0.34 & $-0.52--0.22$ \\
\hline
\end{tabular}

Table 1. Descriptive statistics of ASRS and DOSPERT scales. Note. $N=244$ (132 females, 112 males); ASRS, Adult ADHD Self Report Scale; DOSPERT, Domain-specific Risk-Taking.

their benefit seeking is high. Perceived benefit often elicits attraction, whereas perceived risk evokes repulsion. However, the extent of attraction and repulsion differs across people; sometimes perceived risk may be intrinsically attractive (e.g., sensation seeking). These approaches are captured in Weber et al.'s BDT in the following regression equation:

$$
\text { Preference }(\mathrm{X})=a(\text { Perceived Benefit }(\mathrm{X}))+b(\text { Perceived Risk }(\mathrm{X}))+c
$$

In this equation, preference for alternative $\mathrm{X}$ is a function of the tradeoff between the perceptions of benefit and risk associated with that alternative as well as the person's general attitudes toward benefit and risk (coefficients $a$ and $b$, respectively). Measures of perceptions of benefit and risk are based on self-reports, whereas the attitudes towards benefit and risk are calculated by regressing risk taking behavior on risk perception and benefit perception separately for each individual, and calculating the respective coefficients. The distinction between perception and attitude is crucial for understanding human decision-making according to Weber et al. Studies have indeed shown systematic individual, group, and cultural differences in perceptions of risks and benefits ${ }^{14-16}$. Attitudes towards perceived risk are less affected by context, but they still vary across domains ${ }^{17}$.

To date the role of risk and benefit perceptions of risk-taking behavior in ADHD has not been studied from this BDT perspective, which distinguishes between perceptions and attitudes. More generally, studies so far suggest that individuals with ADHD do not seek risks per $\mathrm{se}^{18}$, but they perceive the outcomes of risk taking behaviors to be either particularly appealing or less risky. In one study, children with ADHD attributed less severe consequences to risky activities ${ }^{19}$. A qualitative study showed that children with ADHD overestimated their physical abilities and disregarded negative consequences of their risk taking ${ }^{20}$. Among adolescents, higher inattention rates were correlated with less negative expectancies regarding the outcomes of cigarette smoking, whereas higher hyperactivity/impulsivity rates were correlated with positive expectancies about smoking ${ }^{21}$. Pedersen, Harty, Pelham, Gnagy, and Molina ${ }^{22}$ found that children with ADHD had lower levels of negative alcohol expectancies, though they also had lower levels of positive expectancies, compared with controls ${ }^{22}$. The finding of different perceptions of the outcomes is consistent with the idea that individuals with ADHD have a "positive illusory bias", i.e. the tendency to provide overly positive reports of their own competence ${ }^{23}$.

In this paper, we report a study using the Domain Specific Risk Taking (DOSPERT) scale. The scale was developed by Blais and Weber ${ }^{24}$ to assess risk taking (an aggregate measure based on likelihood estimates of engaging in 30 different risky behaviors), benefit perception (an aggregate measure based on perception of the benefits received from engaging in each of the 30 behaviors) and risk perception (the level of risk associated with each of the 30 behaviors $)^{24}$. Each of the three DOSPERT scales is divided into five different domains of risk-taking (health and safety, financial, recreational, social, and ethical). For our primary analyses in this research, we adopted a dimensional conceptualization of ADHD, consistent with current taxometric ${ }^{25}$ and genetic ${ }^{26}$ evidence. We hypothesized that (1) ADHD symptoms would be associated with risk taking in all domains, and that perception, rather than attitude, would (2) correlate with ADHD symptoms, and (3) mediate ADHD-related risk taking.

\section{Results}

Preliminary analysis. Table 1 presents descriptive statistics for the ASRS and DOSPERT scores. Normality testing using Kolmogorov-Smirnov test revealed that the following variables, age, ASRS total and sub-dimensions' scores, the DOSPERT calculated total score of perceived benefit attitude, as well as most of the DOSPERT specific domain scores were not distributed normally. For the sake of simplicity, we used the non-parametric statistics to describe and analyze the correlations among all demographic variables, ASRS scales (general, inattention and hyperactivity/impulsivity) and DOSPERT scores. Male and younger participants reported higher risk taking and benefit perception, compared to female and older participants. Consequently, gender and age were used as covariates in mediation analyses. Years of education did not correlate with the DOSPERT scales and was not included in further analyses.

Correlational analysis. Non-parametric correlations among the primary study variables are presented in Table 2. As expected, among the DOSPERT scales, level of benefit perception positively correlated with level of risk taking, and level of risk perception negatively correlated with level of risk taking. In addition, benefit perception negatively correlated with risk perception. ASRS scores positively correlated with levels of risk taking and 


\begin{tabular}{|c|c|c|c|c|c|c|c|c|}
\hline & $\begin{array}{c}\text { ASRS total } \\
\text { score }\end{array}$ & Inattention & Hyperactivity/Impulsivity & Risk-Taking & Benefit-Perception & Risk-Perception & $\begin{array}{c}\text { Perceived-benefit } \\
\text { Attitude }\end{array}$ & $\begin{array}{l}\text { Perceived-risk } \\
\text { Attitude }\end{array}$ \\
\hline Inattention & $0.883^{*}$ & - & & & & & & \\
\hline Risk-Taking & $0.268^{* *}$ & $0.247^{* *}$ & $0.219^{* *}$ & - & & & & \\
\hline Benefit-Perception & $0.286^{* *}$ & $0.289^{* *}$ & $0.219^{* *}$ & $0.717^{* *}$ & - & & & \\
\hline Risk-Perception & -0.005 & 0.005 & -0.002 & $-0.450^{* *}$ & $-0.327^{* *}$ & - & & \\
\hline Perceived-risk Attitude & -0.075 & -0.085 & -0.077 & 0.001 & -0.073 & $-0.246^{* *}$ & $0.533^{* *}$ & - \\
\hline
\end{tabular}

Table 2. Correlations between the ASRS specific dimensions and the DOSPERT scales. Note. $N=244$ (132 females, 112 males); Correlation between Adult ADHD Self Report Scale (ASRS) total, inattention and hyperactivity/impulsivity scores and the Domain-specific Risk-Taking (DOSPERT) scales was conducted using Spearman's rho test. ${ }^{\star} \mathrm{p}<0.05,{ }^{* *} \mathrm{p}<0.01$.

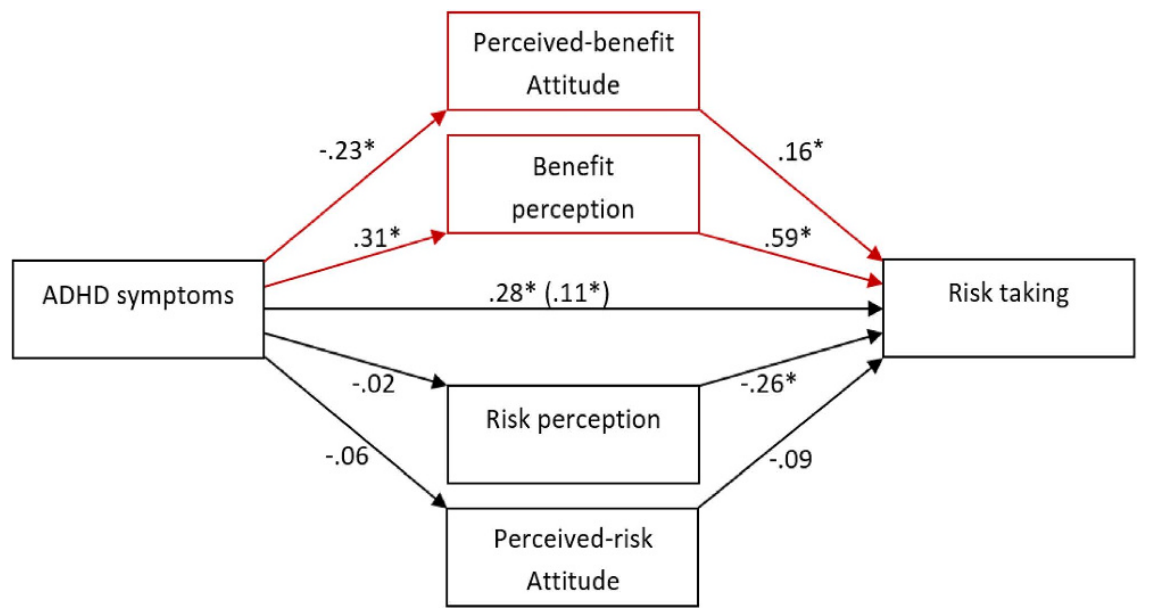

Figure 1. Final mediation path analysis predicting risky behavior. Values reflect standardized regression coefficients of direct and indirect effects of $\mathrm{ADHD}$ on risky behavior. The unstandardized regression coefficient of the direct effect after considering other mediators is presented in parentheses. The covariates of age and gender are not shown in the figure for visual clarity. $N=244$ (132 females, 112 males). ${ }^{\star} p<0.05$.

benefit perception, and negatively correlated with levels of perceived-benefit attitude. In contrast, ASRS score did not correlate with levels of risk perception and perceived-risk attitude.

Inattention and hyperactivity scores showed similar pattern of correlations with the DOSPERT scales, namely, positive correlation with risk taking and benefit perception, negative correlation with perceived-benefit attitude, and no correlation with risk perception and perceived-risk attitude (see Table 2).

Mediation analysis. The primary analysis examined whether the DOSPERT total scores of benefit and risk perception, as well as the derived perceived-benefit attitude and perceived-risk attitude, mediated the relation between the ASRS total score and the DOSPERT total score of risk taking, including age and gender as covariates.

The path analysis in Fig. 1 depicts the direct effects and indirect pathways for the contribution of ADHD symptoms on risk taking through its effects on benefit and risk perception. Together the model accounted for $57.3 \%$ of the variability in risk behavior $(P<0.0001)$. The standardized regression coefficients between ADHD symptoms and risk taking before considering mediators, between ADHD symptoms and benefit perception, and between ADHD symptoms and perceived-benefit attitude were statistically significant $(P<0.001)$. The bootstrapped standardized indirect effect mediated by benefit perception and by perceived-benefit attitude were significant. The indirect effect of ADHD symptoms, mediated by risk perception and perceived-risk attitude were not significant. ADHD symptoms still predicted risk taking after accounting for the indirect effect (see Table 3 for coefficients and CIs).

Additionally, similar mediation analysis was conducted separately for ASRS sub-dimensions. Mediation analysis for each ASRS dimension revealed significant indirect effects mediated by benefit perception and by perceived-benefit attitude. The indirect effect of ADHD symptoms, mediated by risk perception and perceived-risk attitude were not significant. The direct effect of the inattention scores on risk taking was marginally significant, whereas the direct effect of hyperactivity was significant (see Table 3 for coefficients and CIs). 


\begin{tabular}{|c|c|c|c|c|c|c|}
\hline \multirow[b]{2}{*}{ ADHD dimension } & \multirow[b]{2}{*}{ Model $\mathbf{R}^{2}$} & \multicolumn{4}{|c|}{ Indirect effect: } & \multirow[b]{2}{*}{ Direct effect } \\
\hline & & $\begin{array}{c}\text { Benefit } \\
\text { Perception }\end{array}$ & $\begin{array}{c}\text { Risk } \\
\text { Perception }\end{array}$ & $\begin{array}{l}\text { Perceived-benefit } \\
\text { Attitude }\end{array}$ & $\begin{array}{l}\text { Perceived-risk } \\
\text { Attitude }\end{array}$ & \\
\hline Total & 57.3 & $\begin{array}{l}0.184^{*} 95 \% \mathrm{CI} \\
{[0.116,0.224]}\end{array}$ & $\begin{array}{c}0.00495 \% \mathrm{CI} \\
{[-0.028,0.041]}\end{array}$ & $\begin{array}{c}-0.03795 \% \mathrm{CI} \\
{[-0.085,-0.008]}\end{array}$ & $\begin{array}{c}0.00695 \% \mathrm{CI} \\
{[-0.006,0.034]}\end{array}$ & $\begin{array}{l}0.113^{*} 95 \% \mathrm{CI} \\
{[0.020,0.205]}\end{array}$ \\
\hline Inattention & 56.8 & $\begin{array}{l}0.184^{*} 95 \% \mathrm{CI} \\
{[0.114,0.273]}\end{array}$ & $\begin{array}{c}0.00495 \% \mathrm{CI} \\
{[-0.029,0.040]}\end{array}$ & $\begin{array}{c}-0.02995 \% \mathrm{CI} \\
{[-0.077,-0.004}\end{array}$ & $\begin{array}{c}0.00495 \% \mathrm{CI} \\
{[-0.004,0.003]}\end{array}$ & $\begin{array}{c}0.08495 \% \mathrm{CI} \\
{[-0.009,0.176]}\end{array}$ \\
\hline Hyperactivity/Impulsivity & 55.3 & $\begin{array}{l}0.151^{*} 95 \% \mathrm{CI} \\
{[0.079,0.230]}\end{array}$ & $\begin{array}{c}0.00695 \% \mathrm{CI} \\
{[-0.028,0.043]}\end{array}$ & $\begin{array}{c}-0.03695 \% \mathrm{CI} \\
{[-0.088,-0.006]}\end{array}$ & $\begin{array}{c}0.00695 \% \mathrm{CI} \\
{[-0.006,0.038]}\end{array}$ & $\begin{array}{l}0.106^{\star} 95 \% \mathrm{CI} \\
{[0.016,0.197]}\end{array}$ \\
\hline
\end{tabular}

Table 3. Mediation models for general ASRS score and for separate ADHD dimensions. Final mediation path analysis predicting risky behavior separately in each domain. Values reflect standardized regression coefficients of indirect effects and of direct effect (after considering other mediators) of total and subscale scores of ASRS on risky behavior. The covariates of age and gender are not shown in for visual clarity. $N=244$ (132 females, 112 males).

\begin{tabular}{|c|c|c|c|c|}
\hline \multirow[b]{2}{*}{$\begin{array}{l}\text { DOSPERT } \\
\text { domain }\end{array}$} & \multirow[b]{2}{*}{ Model $\mathrm{R}^{2}$} & \multicolumn{2}{|c|}{ Indirect effect: } & \multirow[b]{2}{*}{ Direct effect } \\
\hline & & $\begin{array}{c}\text { Benefit } \\
\text { Perception }\end{array}$ & Risk Perception & \\
\hline Total score & 55.6 & $\begin{array}{c}0.184^{*} 95 \% \mathrm{CI} \\
{[0.050,0.139]}\end{array}$ & $\begin{array}{c}0.00495 \% \mathrm{CI} \\
{[-0.028,0.041]}\end{array}$ & $\begin{array}{c}0.00695 \% \mathrm{CI} \\
{[-0.001,0.012]}\end{array}$ \\
\hline Health/Safety & 48.6 & $\begin{array}{c}0.092 * 95 \% \mathrm{CI} \\
{[0.043,0.208]}\end{array}$ & $\begin{array}{c}0.03495 \% \mathrm{CI} \\
{[-0.023,0.051]}\end{array}$ & $\begin{array}{l}0.178^{*} 95 \% \mathrm{CI} \\
{[0.080,0.275]}\end{array}$ \\
\hline Recreational & 62.3 & $\begin{array}{c}0.117^{\star} 95 \% \mathrm{CI} \\
{[0.043,0.208]}\end{array}$ & $\begin{array}{c}0.01095 \% \mathrm{CI} \\
{[-0.023,0.051]}\end{array}$ & $\begin{array}{c}0.00895 \% \mathrm{CI} \\
{[-0.074,0.091]}\end{array}$ \\
\hline Ethical & 29.3 & $\begin{array}{c}0.110^{*} 95 \% \mathrm{CI} \\
{[0.042,0.172]}\end{array}$ & $\begin{array}{c}0.00995 \% \mathrm{CI} \\
{[-0.010,0.049]}\end{array}$ & $\begin{array}{c}0.13395 \% \mathrm{CI} \\
{[-0.009,0.206]}\end{array}$ \\
\hline Financial & 35.2 & $\begin{array}{c}0.099 * 95 \% \mathrm{CI} \\
{[0.052,0.212]}\end{array}$ & $\begin{array}{c}0.01095 \% \mathrm{CI} \\
{[-0.023,0.051]}\end{array}$ & $\begin{array}{l}0.098^{*} 95 \% \mathrm{CI} \\
{[0.016,0.251]}\end{array}$ \\
\hline Social & 50.2 & $\begin{array}{c}0.04695 \% \mathrm{CI} \\
{[-0.024,0.120]}\end{array}$ & $\begin{array}{c}-0.049 * 95 \% \mathrm{CI} \\
{[-0.098,-0.016]}\end{array}$ & $\begin{array}{c}0.06995 \% \mathrm{CI} \\
{[-0.025,-0.164]}\end{array}$ \\
\hline
\end{tabular}

Table 4. Mediation models for separate risk taking domains. Final mediation path analysis predicting risky behavior separately in each domain. Values reflect unstandardized regression coefficients of indirect effects and of direct effect (after considering other mediators) of ADHD on risky behavior. The covariates of age and gender are not shown in for visual clarity. $N=244$ (132 females, 112 males).

Risk taking domains. Finally, similar mediation analyses were repeated for each domain separately (see Table 4). As noted, perceived risk/benefit attitude were not calculated for each domain and were not included in the model. For four domains, i.e., health/safety, recreational, financial and ethical, ASRS scores positively correlated with levels of risk taking and benefit perception, but not with levels of risk perception. Separate mediation analyses for these four domain revealed indirect effects in which benefit perception, but not risk perception, mediated the association between ASRS score and risk taking. The direct effect of the ASRS score on risk taking remained significant for the health/safety and the ethical domains. On the other hand, regarding the social domain, ASRS scores positively correlated with levels of risk perception, but not with levels of risk taking and benefit perception. Separate mediation analyses for the social domain revealed indirect effects in which risk perception, but not benefit perception, mediated the association between ASRS score and risk taking. The direct effect of the ASRS score on risk taking was not significant (see Table 4 for coefficients and CIs).

\section{Discussion}

This is the first study to examine associations between ADHD symptoms, engagement in real-life risky behaviors and perceptions regarding the benefit and risk of these behaviors. The following discussion will focus on two general findings: 1. ADHD symptoms predicted self-reported engagement in various domains of risk taking behavior. 2. Higher benefit perception of risk taking behaviors, but lower perceived-benefit attitude, correlated with ADHD symptoms and mediated engagement in risk taking behavior.

ADHD symptoms and risk taking behavior. Self-reported ADHD symptoms of inattention and hyperactivity/impulsivity predicted self-reported engagement in a variety of risky behaviors. These findings are in agreement with many studies documenting increased risk taking by people with ADHD. However, most of the studies compared groups of participants with and without clinically diagnosed ADHD. Only seldom do researchers investigate the relation between ADHD symptoms and risk taking in the general population. For example, Kollins et al. ${ }^{4}$ found that each reported inattention and hyperactivity/impulsivity symptom significantly increased the likelihood of regular smoking ${ }^{4}$, and Pingault et al. ${ }^{27}$ reported on a prospective population cohort that inattention predicted nicotine dependence ${ }^{27}$. Our study extends studies such as these on ADHD-related cigarette smoking into risky behavior in general. 
Most of the studies reporting increased risk behavior in persons with ADHD have focused on specific risk behaviors, such as substance use ${ }^{5-7}$, risky driving ${ }^{8}$, and risky sex behavior ${ }^{10}$. Only rarely, do studies on ADHD approach risk taking as a general tendency. Recently, we asked adolescents with and without ADHD to estimate the frequency with which they engaged in 16 different risk-taking behaviors. Total risk taking score (across all behaviors) was higher for adolescents with ADHD than for adolescents without ADHD ${ }^{18}$. The present study confirms the relation between ADHD and the tendency to engage in risk-taking behavior, both in general and in specific real-life domains, including health, recreational, financial and ethical. In contrast to other domains, the positive correlation between ADHD symptoms and risk taking in the social domain was not significant.

ADHD symptoms and risk/benefit perceptions and attitudes. Benefit and risk perception were rarely examined in the ADHD literature. A main finding of the current study is that ADHD symptoms correlate with the perception of the benefits associated with the risky behaviors. Mediation analysis supported a model according to which ADHD symptoms lead to higher benefit perception, which in turn lead to greater engagement in risky behaviors.

Our findings are in accord with one study reporting that adolescents with clinical hyperactivity/impulsivity rates endorsed higher positive smoking expectancies ${ }^{21}$, but not with other studies reporting that individuals with ADHD had lower levels of positive alcohol expectancies compared with individuals without $\mathrm{ADHD}^{22}$, and that individuals with ADHD had lower marijuana expectancies regarding social enhancement and tension reduc$\operatorname{tion}^{28}$. Taking a broader point of view, enhanced perceptions of the benefits of risky behavior is in line with some characteristics the literature ascribes to ADHD decision making. For example, sensation seeking which could potentially enhance the assessment of the benefits ${ }^{29}$ was found to mediate ADHD-associated risk taking ${ }^{30}$. Similarly, delay aversion, which is known to affect ADHD-related behavior ${ }^{31}$, may enhance the perceived benefits of alternatives that do not involve waiting. Future studies should further investigate the conditions under which people with ADHD perceive risky behaviors particularly beneficial.

On the other hand, ADHD symptoms did not correlate with levels of risk perception in our study. This finding is not in accordance with other studies reporting that children with ADHD attributed less severe consequences to risky activities ${ }^{19}$, and disregarded the consequences of their risk taking ${ }^{20}$, that adolescents with clinical inattention rates endorsed less negative expectancies regarding cigarette smoking ${ }^{21}$, and that adults with ADHD had lower marijuana expectancies regarding cognitive and behavioral-impairment ${ }^{28}$. One important methodological difference between our study and the ones mentioned above concerns the measurement of perceptions. Whereas in other studies participants had to estimate the likelihood of specific consequences of substance use, in our study they had to indicate their general "gut level assessment" of the extent to which various behaviors are beneficial or risky. Possibly, these "gut level" perceptions of the benefit of outcomes, and not the likelihood of these outcomes, are more subjected to ADHD symptoms.

According to the $\mathrm{BDT}^{11}$, a distinction should be made between the perceptions of risk and benefit and the attitudes toward these perceptions. Using individual regression analyses, we computed the attitudes towards perceived-risk (risk aversion) and perceived-benefit (benefit seeking) for each participant. Surprisingly, level of ADHD symptoms had a negative correlation with benefit seeking. Together with the previous findings, it seems that stronger ADHD symptoms are associated with higher benefit perception (e.g., smoking cigarette is rated more highly) and lower benefit seeking (i.e., risk taking is less affected by benefit perception). This complex picture may correspond to the variety of findings regarding the complex behavioral and neural response to reward and cost contingencies ${ }^{32,33}$.

The lack of association between ADHD and increased risk seeking seems in accordance with another line of evidence. A popular procedure used for studying risk taking in ADHD involves laboratory-gambling tasks, where subjects are asked to choose between safe and risky alternatives. Groen, Gaastra, Lewis-Evans, and Tucha ${ }^{34}$ found in their review that "half of the studies in children/adolescents (50\%), but only a minority of studies in adults (27\%) reported greater risky performance in individuals with ADHD when compared to normal controls" $(\text { p. } 13)^{34}$. Furthermore, those studies that have shown increased risk taking ${ }^{35}$ have often used tasks in which risk seeking and suboptimal decision-making were confounded (i.e., the riskier alternative was regularly less favorable in terms of its expected value), thus choosing the risky alternative could have reflected either risk seeking or poor decision-making. In a series of experiments conducted recently in our laboratory, we found no differences between ADHD and control groups in choosing between risky and safe alternatives that were equally favorable ${ }^{18}$. Such findings suggest that ADHD is not associated with increased risk seeking, and rather open up the possibility that ADHD involves some disruption in the perception of the choice outcomes, which may lead to non-optimal choice.

Clinical implications. The investigation of the mechanisms underlying impaired decision making among people with ADHD has important clinical implications. Specifically, it informs prescriptive research with the goal of helping people with ADHD to optimize their decision-making and counter their engagement in dangerous activities. Our findings suggest that interventions aimed at reducing risk taking in adults should include measures of their ADHD symptoms as well as their perceptions of the benefits of engaging in risky behaviors. Interventions may be devised in light of the research, which would deal with external regulation and strategies that take into account the individuals' preferences.

Limitations. This study has several limitations: The convenience sampling resulted in limited age distribution and over-representation of individuals with higher education. However, education did not correlate with risk measures. Second, we measured hypothetical risk taking (and used scale ratings), rather than actual engagement in risky behavior. In addition, engagement in risky behaviors was assessed using self-report, which 
was not validated by collateral report. Yet, the present method focuses on participants' motivations and perceptions regarding an unconstrained range of behaviors. Thus, we could elicit one's attitude towards risky behaviors, such as riding a motorbike without a helmet regardless of whether one owns a motorbike or ever rides one in real life.

\section{Methods}

Participants. All experimental protocols were approved by the Shaare Zedek Medical Center Institutional Review Board for research on human subjects. The methods were carried out in accordance with the approved guidelines. Participants were recruited through advertisements in universities, colleges and work places. Gender composition was $54.1 \%$ females $(n=132)$ and $45.9 \%$ males. The sample's mean age was $34.24 \pm 11.78$, and mean years of education was $14.50 \pm 1.67$. Twenty-three participants (9.4\%) reported that they had been formally diagnosed with ADHD. Subjects did not receive monetary compensation for participation.

Protocol and Measures. Meetings with participants took place in a quiet room. Written informed consent was obtained from all subjects, followed by completion of a demographic questionnaire, the Adult ADHD Self-Report Scale (ASRS) and the Domain Specific Risk-Taking (DOSPERT) scale.

Demographic questionnaire: Participants provided background information on age, gender, and history of diagnosis of ADHD.

The Hebrew version of the ASRS-V1.1 ${ }^{36,37}$ is a dimensional measure of ADHD symptoms. It includes 18 items corresponding to the DSM diagnostic criteria of ADHD, each measured for its frequency on a Likert scale ranging from 1 (never) to 5 (very often). The questionnaire has high internal consistency $(\alpha=0.88)$. As an ADHD screener, the scale's sensitivity and specificity are $68.4 \%$ and $99.6 \%$, respectively ${ }^{38}$.

Domain-Specific Risk-Taking (DOSPERT): Blais and Weber's version of the DOSPERT (2006) scale assesses risk taking in five domains: health/safety, finance, ethical choices, social interaction, and recreation ${ }^{24}$. The DOSPERT measures risk taking, perceived benefits and risks of 30 activities, using seven-point Likert scales (risk-taking: $1=$ extremely unlikely, $7=$ extremely likely; benefit perception: $1=$ no benefits, $7=$ great benefits; risk perception: $1=$ not at all risky, $7=$ extremely risky). The three DOSPERT scales can each be broken apart into five subscales representing specific domains of risk-taking (i.e., ethical, financial, health and safety, recreational, social). Harrison, Young, Butow, Salkeld, and Solomon ${ }^{39}$ recommended the DOSPERT for its ability to assess risk taking in different everyday domains and to separate perceptual and attitudinal reasons for taking risks ${ }^{39}$. The scale has adequate internal-consistency and moderate test-retest reliability estimates, and it provided evidence for the factorial and convergent/discriminant validity of the scores with respect to constructs such as sensation seeking, dispositional risk taking, intolerance for ambiguity, and social desirability ${ }^{11}$. Construct validity was also assessed via correlations with the results of a risky gambling task as well as with tests of gender differences ${ }^{11}$. The DOSPERT scale was translated into Hebrew by our team employing scientific translation rules, including multiple translators and independent back-translations.

Statistical Analysis. Scores for the ASRS were computed by summing responses to the 18 items together, as well as separately for inattention and for hyperactivity/impulsivity. Scores for risk-taking, benefit perception and risk perception were computed in two ways. First, by averaging the responses to all 30 behaviors and second, by averaging for each domain separately the responses to all six relevant behaviors. Using the BDT regression equation noted above for each participant, we calculated the two coefficients ( $a$ and $b$ ) which index the individual attitudes towards benefit and risk. Since each domain scale involved only six items, attitudes could not be reliably calculated with a separate regression for each individual and for each domain ${ }^{40}$. Observations that were more than 3.01 standard deviations away from the group mean were defined as outliers, according to Grubbs G outlier test ${ }^{41}$ for $N>=25$ and alpha $=0.01$. Outliers were replaced by the 3.0 SD values, according to the Winsorising method, as recommended by Tabachnick and Fidell ${ }^{42}$. This method of dealing with extreme case values preserves the increased value of the outlier sample, whilst ameliorating its disproportionate influence on the data. Preliminary analyses were conducted to examine the normative distribution of each variable using the Kolmogorov-Smirnov test, and to examine whether there were any statistically significant associations between demographic variables and our study variables.

Next, we examined correlations between the total ASRS score and the DOSPERT scores. Tests of significance were two-sided. Finally, direct and indirect effects of ADHD symptoms on risk-taking behavior were calculated using the multiple mediation approach and SPSS macro (PROCESS, Model 6) provided by Hayes ${ }^{43}$. Following procedures recommended by Preacher and Hayes ${ }^{44}$, a multiple mediation model involves (a) an analysis of the total indirect effect-the aggregate mediating effect of all the mediators being examined and (b) an analysis of the specific indirect effect-the mediating effect of a specific mediator ${ }^{44}$. The significance of the indirect effects was tested via bootstrap analysis, which is commonly performed in multiple mediator analyses given its advantage of greater statistical power without assuming multivariate normality in the sampling distribution, assuming only the sample is representative of the population ${ }^{44-46}$. Mediation is demonstrated via a statistically significant indirect effect (i.e., if the $95 \%$ bias-corrected confidence interval for the parameter estimate does not contain zero). All analyses were conducted using SPSS 21.0 including an SPSS macro designed for assessing multiple mediation models ${ }^{44}$. Additional analyses included separate correlation and mediation analyses of the relations between the specific ASRS scales, namely, inattention and hyperactivity/impulsivity, and the total DOSPERT score. 


\section{References}

1. American Psychiatric Association. Diagnostic and Statistical Manual of Mental Disorders, 5th edition, American Psychiatric Press, Washington D.C. (2013).

2. Faraone, S. V. et al. Attention-deficit/hyperactivity disorder. Nature Reviews: Disease Primers 1, 1-23, doi:10.1038/nrdp.2015.20 (2015).

3. Nigg, J. T. Attention-deficit/hyperactivity disorder and adverse health outcomes. Clinical Psychology Review, 33, 215-228, doi:10.1016/j.cpr.2012.11.005 (2013).

4. Kollins, S. H., McClernon, F. J. \& Fuemmeler, B. F. Association between smoking and attention-deficit/hyperactivity disorder symptoms in a population-based sample of young adults. Archives of general psychiatry 62(10), 1142-1147, doi:10.1001/ archpsyc.62.10.1142 (2005).

5. Charach, A., Yeung, E., Climans, T. \& Lillie, E. Childhood attention-deficit/hyperactivity disorder and future substance use disorders: Comparative meta-analyses. Journal of the American Academy of Child and Adolescent Psychiatry 50, 9-21, doi:10.1016/j. jaac.2010.09.019 (2011).

6. Lee, S. S., Humphreys, K. L., Flory, K., Liu, R. \& Glass, K. Prospective association of childhood attention-deficit/hyperactivity disorder (ADHD) and substance use and abuse/dependence: A meta-analytic review. Clinical Psychology Review 31, 328-341, doi:10.1016/j.cpr.2011.01.006 (2011).

7. Molina, B. S. G. \& Pelham, W. E. Attention-deficit/hyperactivity disorder and risk of substance use disorder: Developmental considerations, potential pathways, and opportunities for research. Annual review of clinical Psychology 10, 607-639, doi:10.1146/ annurev-clinpsy-032813-153722 (2014).

8. Barkley, R. A. \& Cox, D. A review of driving risks and impairments associated with attention-deficit/hyperactivity disorder and the effects of stimulant medication on driving performance. Journal of Safety Research 38, 113-128, doi:10.1016/j.jsr.2006.09.004 (2007).

9. Breyer, J. L. et al. Young adult gambling behaviors and their relationship with the persistence of ADHD. Journal of Gambling Studies 25, 227-238, doi:10.1007/s10899-009-9126-z (2009).

10. Sarver, D. E., McCart, M. R., Sheidow, A. J. \& Letourneau, E. J. ADHD and risky sexual behavior in adolescents: Conduct problems and substance use as mediators of risk. Journal of Child Psychology and Psychiatry 55, 1345-1353, doi:10.1111/jcpp.12249 (2014).

11. Weber, E. U., Blais, A. R. \& Betz, E. A Domain specific risk-attitude scale: Measuring risk perceptions and risk behaviors. Journal of Behavioral Decision Making 15, 263-290, doi:10.1002/bdm.414 (2002).

12. Sonuga-Barke, E. J. S. \& Fairchild, G. Neuroeconomics of attention-deficit/hyperactivity disorder: Differential influences of medial, dorsal, and ventral prefrontal brain networks on suboptimal decision making? Biological Psychiatry 72, 126-133, doi:10.1016/j. biopsych.2012.04.004 (2012).

13. Schonberg, T., Fox, C. R. \& Poldrack, R. A. Mind the gap: Bridging economic and naturalistic risk-taking with cognitive neuroscience. Trends in cognitive sciences 15(1), 11-19, doi:10.1016/j.tics.2010.10.002 (2011).

14. Bontempo, R. N., Bottom, W. P. \& Weber, E. U. Crosscultural differences in risk perception: A model-based approach. Risk Analysis 17, 479-488, doi:10.1111/j.1539-6924.1997.tb00888.x (1997).

15. Figner, B. \& Weber, E. U. Who takes risk when and why? Determinants of risk-taking. Current Directions in Psychological Science 20, 211-216, doi:10.1177/0963721411415790 (2011).

16. Slovic, P. Trust, emotion, sex, politics, and science: Surveying the risk-assessment battlefield. Risk analysis 19(4), 689-701, doi:10.1111/j.1539-6924.1999.tb00439.x (1999).

17. Weber, E. U. \& Hsee, C. K. Cross-cultural differences in risk perception, but cross-cultural similarities in attitudes towards perceived risk. Management Science 44, 1205-1217, doi:10.1287/mnsc.44.9.1205 (1998).

18. Pollak, Y. et al. Do Adolescents With Attention-Deficit/Hyperactivity Disorder Show Risk Seeking? Disentangling Probabilistic Decision Making by Equalizing the Favorability of Alternatives. Journal of abnormal psychology 125(3), 387-398 http://dx.doi. org/10.1037/abn0000140 (2016).

19. Farmer, J. E. \& Peterson, L. Injury risk factors in children with attention deficit hyperactivity disorder. Health Psychology 14, 325-332, doi:10.1037/0278-6133.14.4.325 (1995).

20. Bruce, B. R., Ungar, M. \& Waschbusch, D. A. Perceptions of risk among children with and without attention deficit/hyperactivity disorder. International Journal of Injury Control and Safety Promotion 16, 189-196, doi:10.1080/17457300903306914 (2009).

21. Foster, I., Racicot, S. \& McGrath, J. J. Attention-deficit/hyperactivity disorder subtype differentially predicts smoking expectancies in adolescents. The Journal of Adolescent Health 51,393-399, doi:10.1016/j.jadohealth.2012.01 (2012).

22. Pedersen, S. L., Harty, S. C., Pelham, W. E., Gnagy, E. M. \& Molina, B. S. G. Differential associations between alcohol expectancies and adolescent alcohol use as a function of childhood ADHD. Journal of studies on alcohol and drugs 75(1), 145-152, doi:10.15288/ jsad.2014.75.145 (2014).

23. Owens, J. S., Goldfine, M. E., Evangelista, N. M., Hoza, B. \& Kaiser, N. M. A critical review of self-perceptions and the positive illusory bias in children with ADHD. Clinical Child and Family Psychology Review, 10, 335-351, doi:10.1007/s10567-007-0027-3 (2007).

24. Blais, A. R \& Weber, E. U. A domain-specific risk-taking scale for adult populations. Judgment and Decision Making 1, 33-47, doi:10.1037/t13084-000 (2006).

25. Coghill, D. \& Sonuga-Barke, E. J. S. Annual research review: Categories versus dimensions in the classification and conceptualisation of child and adolescent mental disorders-implications of recent empirical study. Journal of Child Psychology and Psychiatry 53(5), 469-489, doi:10.1111/j.1469-7610.2011.02511.x (2012).

26. Nikolas, M. A. \& Burt, S. A. Genetic and environmental influences on ADHD symptom dimensions of inattention and hyperactivity: a meta-analysis. Journal of Abnormal Psychology 119(1), 1-17, doi:10.1037/a0018010 (2010).

27. Pingault, J. B. et al. Childhood trajectories of inattention, hyperactivity and oppositional behaviors and prediction of substance abuse/dependence: a 15-year longitudinal population-based study. Molecular psychiatry 18(7), 806-812, doi:10.1038/mp.2012.87 (2013).

28. Harty, S. C., Pedersen, S. L., Gnagy, E. M., Pelham Jr, W. E. \& Molina, B. S. ADHD and marijuana-use expectancies in young adulthood. Substance use \& misuse 50(11), 1470-1478, doi:10.3109/10826084.2015.1018 (2015).

29. Maslowsky, J., Buvinger, E., Keating, D. P., Steinberg, L. \& Cauffman, E. Cost-benefit analysis mediation of the relationship between sensation seeking and risk behavior among adolescents. Personality and Individual Differences 51, 802-806, doi:10.1016/j. paid.2011.06.028 (2011).

30. Graziano, P. A. et al. ADHD symptomatology and risky health, driving, and financial behaviors in college: The mediating role of sensation seeking and effortful control. Journal of Attention Disorders 19, 179-190, doi:10.1177/1087054714527792 (2014).

31. Sonuga-Barke, E. J. S., Taylor, E., Sembi, S. \& Smith, J. Hyperactivity and delay aversion-I. The effect of delay on choice. Journal of Child Psychology and Psychiatry 33, 387-398, doi:10.1111/j.1469-7610.1992.tb00874.x (1992).

32. Luman, M., Oosterlaan, J. \& Sergeant, J. A. The impact of reinforcement contingencies on AD/HD: A review and theoretical appraisal. Clinical Psychology Review 25, 183-213, doi:10.1016/j.cpr.2004.11.001 (2005).

33. Luman, M., Tripp, G. \& Scheres, A. Identifying the neurobiology of altered reinforcement sensitivity in ADHD: a review and research agenda. Neuroscience \& Biobehavioral Reviews, 34, 744-754, doi:10.1016/j.neubiorev.2009.11 (2010).

34. Groen, Y., Gaastra, G. F., Lewis-Evans, B. \& Tucha, O. Risky behavior in gambling tasks in individuals with ADHD-A Systematic Literature Review. PLoS ONE, 8, e74909, doi:10.1371/journal.pone.0074909 (2013). 
35. Bjork, J. M. \& Pardini, D. A. Who are those "risk-taking adolescents"? Individual differences in developmental neuroimaging research. Developmental Cognitive Neuroscience 11, 56-64, doi:10.1016/j.dcn.2014.07.008 (2014).

36. Kessler, R. C. et al. The World Health Organization Adult ADHD Self-Report Scale (ASRS): a short screening scale for use in the general population. Psychological medicine 35(02), 245-256, doi:10.1017/s0033291704002892 (2005).

37. Zohar, A. H. \& Konfortes, H. Diagnosing ADHD in Israeli adults: The psychometric properties of the adult ADHD Self Report Scale (ASRS) in Hebrew. The Israeli Journal of Psychiatry and related sciences 47(4), 308-15 (2010).

38. Adler, L. A. et al. Validity of pilot adult ADHD self- report scale (ASRS) to rate adult ADHD symptoms. Annals of Clinical Psychiatry, 18, 145-148 doi:10.1080/10401230600801077 (2006).

39. Harrison, J. D., Young, J. M., Butow, P., Salkeld, G. \& Solomon, M. J. Is it worth the risk? A systematic review of instruments that measure risk propensity for use in the health setting. Social science \& medicine 60(6), 1385-1396, doi:10.1016/j.socscimed.2004.07 (2005).

40. Green, S. B. How many subjects does it take to do a regression analysis? Multivariate Behavioral Research 26, 499-510, doi:10.1207/ s15327906mbr2603_7 (1991).

41. Grubbs, F. E. Procedures for detecting outlying observations in samples. Technometrics 11(1), 1-21, doi:10.1080/00401706.1969.1049 (1969).

42. Tabachnick, B. G. \& Fidell, L. S. Using Multivariate Statistics. Boston: Allyn and Bacon, (2001).

43. Hayes, A. F. Introduction to Mediation, Moderation, and Conditional Process Analysis: A Regression-Based Approach. Guilford, New York, NY, (2013).

44. Preacher, K. J. \& Hayes, A. F. Asymptotic and resampling strategies for assessing and comparing indirect effects in multiple mediator models. Behavior research methods 40(3), 879-891, doi:10.3758/brm.40.3.879 (2008).

45. Mallinckrodt, B., Abraham, W. T., Wei, M. \& Russell, D. W. Advances in testing the statistical significance of mediation effects. Journal of Counseling Psychology 53(3), 372-378, doi:10.1037/0022-0167.53.3.372 (2006).

46. Williams, J. \& MacKinnon, D. P. Resampling and distribution of the product methods for testing indirect effects in complex models. Structural Equation Modeling 15(1), 23-51, doi:10.1080/10705510701758166 (2008).

\section{Acknowledgements}

The authors want to thank Maayan Ochbaum and Natalie Zozel for their excellent help in running the study.

\section{Author Contributions}

Y.P., I.Y., E.J.S.S.-B. and R.S. designed the study, R.S. and H.A. collected and input the data. Y.P. analyzed the data, R.S. wrote the paper. Y.P., E.J.S.S.-B. and I.Y. reviewed and revised the paper.

\section{Additional Information}

Competing financial interests: Edmund Sonuga-Barke: Speaker fees, consultancy, research funding and conference support from Shire Pharma. Speaker fees from Janssen Cilag, Consultancy from Neurotech solutions, Aarhus University, Copenhagen University and Berhanderling, Skolerne, Copenhagen, KU Leuven. Book royalties from OUP and Jessica Kingsley. Grants awarded from MRC, ESRC, Wellcome Trust, Solent NHS Trust, European Union, Child Health Research Foundation New Zealand, NIHR, Nuffield Foundation, Fonds Wetenschappelijk Onderzoek-Vlaanderen (FWO), MQ-Transforming Mental Health.

How to cite this article: Shoham, R. et al. ADHD-associated risk taking is linked to exaggerated views of the benefits of positive outcomes. Sci. Rep. 6, 34833; doi: 10.1038/srep34833 (2016).

(c) (i) This work is licensed under a Creative Commons Attribution 4.0 International License. The images or other third party material in this article are included in the article's Creative Commons license, unless indicated otherwise in the credit line; if the material is not included under the Creative Commons license, users will need to obtain permission from the license holder to reproduce the material. To view a copy of this license, visit http://creativecommons.org/licenses/by/4.0/

(c) The Author(s) 2016 